\title{
A review of literature relevant to the experiences of irish parents in the mediation of their children's use of internet connected devices
}

\begin{abstract}
This review sets out to explore the relatively new and unique parental experience of mediating children's use of Internet connected devices (ICDs) in Ireland. A coherent understanding of the core concepts that emerged from the literature is presented in a way that connects broad theoretical concepts to specific contexts. An overview of parental experience and the relationship between parental experience and the theoretical aspects of psychology, counselling and psychotherapy is presented. ICDs are briefly explained and a working definition is established for the purpose of this review. The literature on parental mediation of children's use of ICDs is explored and segmented into risks and benefits. Literature on parental strategies for mediation of children's use of ICDs is reviewed. The relationship between trust, parenting styles and the concept of child self-regulation is explored. Literature is reviewed to place an Irish context on the parental experience in the mediation of ICDs. The review concludes with a discussion and summary conclusions based on the literature reviewed that creates a chain of evidence in support of additional research.
\end{abstract}

Keywords: parental mediation, children on-line, risks and benefits, internet devices, Ireland
Volume 3 Issue 3 - 2015

\author{
Sean Meehan,' John Hickey² \\ 'Lecturer, Irish College of Humanities and Applied Sciences, \\ Ireland \\ ${ }^{2}$ Director, Clinical Supervision Services Ireland
}

Correspondence: Sean Meehan, Irish College of Humanities and Applied Sciences, Walton House, Lonsdale Road, Castletroy, Limerick, Ireland, Email sean.meehan I0I@gmail.com

Received: June 23,2015 | Published: August 08, 2015
Abbreviations: ICD's, internet connected devices; IoT, internet of things; STAI, state trait anxiety inventory

\section{Introduction}

The term generation text, coined by Osit, ${ }^{1}$ refers to children in contemporary society that engage with technology as part of their childhood experience. In one minute on the Internet there are 20 victims of identity theft, 1300 new mobile users, 1.3 million videos are viewed, two million Google search's completed and 20million photos viewed. ${ }^{2}$ Parents now have a new experience that simply did not exist a generation ago - internet connected devices (ICDs). ${ }^{2}$ Implicit in this new parental experience, the mediation of children's use of ICDs, there are a series of challenges and opportunities. The approaches that parents use for past media technologies, such as television may, appear outmoded and ineffective against the enormous volume of new devices and ways of connecting to others and being online. The parental experience can be further understood as the parent having to choose to develop new technical skills to understand the language connected with technology or where the parent is required to manage a child that may have greater technical skills then themselves. However, the new experience of parental mediation of ICD technology should not obscure the inherent elements of parenting such as communication, knowledge of the individual child, parenting styles, trust and understanding the child's ability or propensity to deceive or lie. ${ }^{1,3-7}$ Parents experience the internal conflict of having to offer the child more autonomy as they develop towards independent adulthood while trying to keep them safe in their early stages of individual autonomy.

The connection of parental experience to psychology, counselling and psychotherapy theory

The Penguin Dictionary of Psychology ${ }^{8}$ uses easily understood language to define experience as "any event through which one has lived, the knowledge gained from those events" and the "sum of knowledge accumulated". However that definition does not fully describe how the experience was felt. Within this review the definition of human experience is taken as "to do or see (something) or have (something) happen to you: to feel or be affected by (something): to learn (by experience)". 9 Parental experiences are taken as human experiences that occur within the context of parenting. ${ }^{10}$

Psychologists, counsellors and psychotherapists use different evidence based theoretical orientations as a "map to guide them" in their interactions with clients. ${ }^{11}$ There are a number of elements that can be considered common across different approaches including the client's own experience and the therapeutic relationship. ${ }^{11-14}$ The lineage of parental experiences can be seen in the development of different theoretical approaches. Parental experiences were included in the basis of Freud's ${ }^{15}$ psychoanalytical theory. The parentchild relationship formed the basis of development for Bowlby's ${ }^{16}$ attachment theory. The person-centred approach of Roger's from the 1960 s is viewed as having had an immense impact on types of parenting styles and techniques. ${ }^{17}$ Authors have highlighted the parent-child experience as being a central element of family systems therapy. ${ }^{11,13}$ The parent-child relationship is contended by Whitcombe ${ }^{18}$ as a central tenet in the theoretical understanding of parental alienation and to be of relevance to clinical psychology. The impact of parental alienation is characterised by Whitcombe ${ }^{18}$ as having short, medium and long-term effects including depression, substance abuse, damaged self-esteem and issues with lack of trust. Addressing issues such as depression, substance abuse and low self-esteem are often the goals of various treatment interventions across the spectrum of approaches in psychology, counselling and psychotherapy. ${ }^{11,13,18} \mathrm{~A}$ critical assessment of the various theories infers that parental experiences play a critical role in the theoretical understanding of personal experiences (for both the child and adult) and that while approaches may differ in how they treat the parental experience there seems to be a general acceptance as to the importance of parental experience. 


\section{Internet connected devices (ICDs)}

There are more devices connected to the Internet than there are people in the world. ${ }^{19}$ The Internet of Things (IoT), according to Covington \& Carskedden ${ }^{19}$ can be conceptualised as any object that can directly interact with the Internet. Being connected to the Internet means that devices continually share data with people and other devices. ${ }^{2}$ Additionally, connection to the Internet also means interaction with a remote form of information storage based on the Internet known as the cloud. ${ }^{2}$ Operationally, ICDs are understood as any device that provides a way that information flows between people and things (other devices). ${ }^{2,19}$ The range of ICDs include, but are not limited to, desktop computers, laptop computers, tablet platforms, smartphones, gaming consoles and smart televisions. ${ }^{2,19}$ Critically, it could be observed that change is a constant component of ICDs implying that parental mediation strategies need to be dynamic and adjust to change in types of technology.

\section{Parental mediation}

Parental mediation, according to Clark, ${ }^{5}$ should be taken as a means of recognising that parents take a role in managing and regulating their children's Internet experiences. Furthermore, Kirwil ${ }^{20}$ contends that parental mediation of children's Internet use can be defined "as the regulatory strategies that parents introduce to maximize benefits and minimize their children's risks from Internet use". A minor difference of understanding is evident between Clark's ${ }^{5}$ and Kirwil's ${ }^{20}$ view of parental mediation in that Kirwil infers that the experience can be positive through the use of the words 'maximise' and 'benefits' and negative through the words 'minimise' and 'risk'. In this review, Kirwil' ${ }^{20}$ definition of parental mediation is used.

Critically, a number of observations can be made about the definitions of parental mediation offered by both Clark ${ }^{5}$ and Kirwil. ${ }^{20}$ Both Clarke ${ }^{5}$ and Kirwil ${ }^{20}$ should be recognised for offering a contemporary understanding of parental mediation that builds on mediation theories concerning the influence of television to now specifically include the Internet. However, it can be critically observed that neither Clark ${ }^{5}$ nor Kirwil ${ }^{20}$ identified tactics as an element of parental mediation strategies. Strategy can be viewed as an overarching element that describes an objective, or be thought of as the 'what is to be achieved', whereas tactics, the 'how to', refers to the means and methods used to achieve the strategic objectives. ${ }^{21,22}$ The difference between parental mediation strategies and tactics can be illustrated as a parental strategic objective to protect the child from unwanted contact from strangers on the internet and associated parental tactics may be to block pop-up advertisements, or ban a child from joining social media sites. Interestingly, Livingstone \& Helsper ${ }^{23}$ contend that parental monitoring can be covert or overt. The concept that parental monitoring can be covert or overt, as suggested by Livingstone \& Helsper, ${ }^{23}$ could be viewed critically suggesting that parental mediation strategies or tactics could also be covert or overt in nature. Neither Clarke, ${ }^{5}$ Kirwil $^{20}$ nor Livingstone \& Helsper ${ }^{23}$ identify dynamic components for parental mediation which illustrate how or when parental mediation strategies change, or if parental mediation strategies may be used as a method to control general behaviour.

Critically, it could be observed that Clark's ${ }^{5}$ view does not cover parents that do not mediate the children's Internet experiences or if parents choose not to mediate based on the experience of fear or trust or other factors. A critical observation of both Kirwil's $\mathrm{s}^{20}$ and Clark's $\mathrm{s}^{5}$ definition of parental mediation is that there is no gender difference recognised within the parent-child relationship. However, Biddulph ${ }^{24}$ contends that parents have different lived experiences of parenting boys and girls. An additional critical observation is the implied connection between risk and negative outcome by Kirwil. ${ }^{20}$ It does not promote the consideration that the outcome from engaging in risk could be positive or negative.

\section{Parental mediation: potential risks}

Research by Nauert ${ }^{25}$ presents data based on parental concerns and experiences in mediating the Internet in the United States of America (U.S.A.) indicating that approximately $66 \%$ of parents with children online are concerned with online sexual predators and loss of privacy, while approximately $50 \%$ of the parent population are concerned or very concerned about children viewing pornography. Other parental concerns identified by Nauer ${ }^{25}$ about children's online activities include those of online gaming, gambling and bullying activity (child being the bully or being bullied). The identification of online gaming by Nauert ${ }^{25}$ as a parental concern seems to be supported by governing bodies. It is highlighted by $\mathrm{Calder}^{26}$ that the American Psychological Association (APA) passed a resolution calling for the reduction of violent content in interactive media and video games, and that the APA has created a task force to review research between interactive media and gaming violence and the prevalence of youth violence. The use of categories by Nauert ${ }^{25}$ helps to the identify the different types of concerns or worries that parents experience about children's use of the Internet and quantify the size of those different categories of concern. However, Nauert' $\mathrm{s}^{25}$ research was not designed to capture the parental lived experience of what it is to experience those concerns or worries. Implicit (but not specifically identified) in Nauert' $\mathrm{s}^{25}$ analysis is that the risk can be interpreted as two different types of risk; a risk of exposure to age-inappropriate material for the child and a risk in the form of worry and concern to the parent.

Worry can be understood as an anxious feeling or emotion about an actual or potential problem. ${ }^{27}$ Furthermore, Reber et al. ${ }^{8}$ identify that worry is a theorised component of anxiety. Critically, Reber et al., ${ }^{8}$ distinguish fear from anxiety in that fear can be considered as a reaction to a present danger whereas anxiety relates to an anticipated or imagined danger. However, Reber et al., ${ }^{8}$ do not define or make reference to the concept of parental anxiety but do refer to parental behaviours as being connected to the provision of parental care, protection and nurturing of children. Critically, the understanding of parental behaviour offered by Reber et al., ${ }^{8}$ seems to broadly match Santrock's view of parental experiences, however it should be noted that Santrock ${ }^{10}$ captures the experience rather than just the behaviour.

General anxiety according to Reber et al. ${ }^{8}$ is "a vague unpleasant state" often characterised by apprehension, dread, distress or uneasiness. Parental anxiety has been measured in parent-child orientated research such as that of Clarke, Cooper \& Creswell, ${ }^{28}$ Cobham et al., ${ }^{29}$ Geggel et al., ${ }^{30}$ and Pereira et al., ${ }^{31}$ Research however understands parental anxiety primarily as being a score on the State Trait Anxiety Inventory (STAI). Here, a number of observations can be made. The literature reviewed did not define parental anxiety except by reference to STAI scores. It could be observed that there is no item on Spielberger' ${ }^{32}$ original STAI inventory that seeks to understand levels of trust. It could be observed that when assessing an individual's anxiety there may be no need to consider trust. However, when considering a parent-child relationship, levels of trust, or the experience of trust, may relate to levels of anxiety. The literature of Clarke et al., ${ }^{28}$ Cobham et al., ${ }^{29}$ Geggel et al., ${ }^{30}$ and Pereira et al., ${ }^{31}$ infers an understanding of parental anxiety as a person's experience of anxiety related to their role as a parent. Within this review the working understanding or operational definition of parental anxiety 
is the experience of anxious feelings or emotions about anticipated or imagined danger experienced by a person in their role as parent. When this operational definition of parental anxiety is used it becomes possible to interpret the parental worries and concerns identified by Nauert ${ }^{25}$ as a form of parental anxiety risk. The risk of parental anxiety can be illustrated as the potential worry or anxiety that parents may experience about the dangers associated with children viewing violent or pornographic content. The breath of parental anxiety could be characterised as including parental anxiety about confronting a child about online activities or the experience of parental anger as a form of expression for parental anxiety about trying to control the enormous volume of information provided by ICDs. Parental anxiety, or the risk of parental anxiety, has been highlighted by Richardson ${ }^{33}$ in identifying that children have shared extreme and illegal pornographic material (images of children or images containing animals) in playgrounds and schoolyards. The illegal content highlights one form of risk. Not all risk may be illegal. According to Bartlett, ${ }^{34}$ teenage girls have engaged in a risk behaviour game known as bag a peado where girls dangle older men along online for fun. However, Bartlett ${ }^{34}$ highlights the risk involved as online predators spend hours monitoring potential victims' social networks to learn about interests such as favourite films or places visited. This monitoring is done with a view to building rapport and an intent to groom the child. ${ }^{34}$ Prior research has indicated that the age of the child is a factor in how risk is understood and mediated by parents. ${ }^{23,26}$ It would seem prudent to understand how exposure to inappropriate content, including online risk behaviours, may or may not impact the parent-child relationship.

Research highlighted by Ross ${ }^{7}$ indicates the potential impact that may be experienced by curious adolescents that may accidentally or intentionally access uncensored and potentially harmful ICD content. The findings suggest a positive correlation between children viewing content that glamorises risk behaviours such as drinking, drug use or violent behaviour and children's tendency to engage in those behaviours. ${ }^{7}$ Similarly, media content has also been shown to influence adolescent sexual attitudes and behaviours. Research shows $66 \%$ of boys and $40 \%$ of girls reported wanting to try some of the sexual behaviours they saw in the media. ${ }^{7}$ The link between young people viewing graphically violent or extreme sexualised content and the potentially devastating consequences of engaging in risk behaviour is illustrated by a connection to an online risk behaviour game, Nek-nominations. ${ }^{7,35-37}$ Illustrations of types of risk behaviour include drinking from toilet bowls, drinking foul water, drinking litres of cooking oil, drinking while driving, drinking more than a week's units of alcohol in minutes, being set alight while drinking or being hit by sticks, concrete blocks or flares while drinking. ${ }^{35,36,38,39}$ A stark contrast exists between effect and popularity of the risk behaviour contained in Nek-nominations as it has been linked to youth deaths in the United Kingdom, U.S.A. and Ireland which contrasts sharply with one Nek-nominations social media site having 36,000 likes. ${ }^{35-37}$ Parents, according to Ross, ${ }^{7}$ seek to preserve, protect and manage the experience of being young. Critically, parental understanding of the types of risks that children may be exposed to may aid parents in seeking to preserve the emotional experience of youth during childhood. However, it could be observed that parents maybe unaware of risks that children have been exposed to as the child may not have felt at risk, felt the need to communicate with the parent or thought that the parent may be embarrassed or may have feared a parental over-reaction to risk content.

The theme of parental anxiety and online risk to children seems to transgress geographical and cultural boundaries, as Livingstone
\& Haddon $^{40}$ suggest. Parents within the United Kingdom (U.K.) have similar concerns and worries to parents in the U.S.A.. ${ }^{25,40}$ Furthermore, Livingstone \& Haddon ${ }^{40}$ specified four different online risk experiences that parents mediate:

\section{Content risk}

\section{Contact risk}

\section{Conduct risk, and}

\section{Violation of privacy}

Content risk can be viewed as the experience of inappropriate content while contact risk can be understood as contact that may initially occur online but may evolve to meeting the online contact in person..$^{20,40}$ Conduct risk may be taken to include cyber-bullying and violation of privacy may be taken to infer parental concerns, worries or anxiety about online contacts, phishing for information for unknown purposes (but may include approaches from online predators). ${ }^{20,25,40}$

Research conducted by Livingstone \& Haddon ${ }^{40}$ explored a broad range of concepts ranging from the nature of children's Internet use through to risks associated with Internet use and the data may be considered thorough and robust. The data for the 12-17year-old category provides a measure of the different risks experienced through Internet use (at least) once a week. In the 12-17year-old age group, 44\% reported ending up on a pornographic site while accidentally looking for something else, 9\% deliberately logged onto a pornographic site and 3\% were sent pornographic material by someone they met online ${ }^{40}$ Accidental exposure to violent imagery for the 12-17yearolds was $27 \%$ with $14 \%$ visiting the sites on purpose while $46 \%$ have given out personal information. ${ }^{40}$ More than one third (36\%) have online contacts that they have never met in person while just under a tenth $(9 \%)$ have met online contacts face to face. A third of children in Livingstone \& Haddon's ${ }^{40}$ research reported receiving nasty or hurtful comments online. Livingstone \& Haddon's ${ }^{40}$ research contended that children's age, gender and online skills were predictors of online risk exposure and presented that parental mediation was ineffective in the reduction of online risk. A critical observation of Livingstone $\&$ Haddon's ${ }^{40}$ research should recognise the informative value that understanding the size of exposure to the differing risk types provide. It should be noted that the risks identified did not capture the full breath of risks, nor was the nature of the qualitative experience of parental mediation explored.

Research by Ebbeling et al. ${ }^{41}$ highlights the inverse relationship between childhood physical activity and time spent interacting with ICDs thus connecting children's use of ICDs to childhood obesity. The complications from childhood obesity have also been linked to musculoskeletal problems and also to psychosocial issues of specific interest to the areas of psychology, counselling and psychotherapy including poor self-esteem, depression and eating disorders. ${ }^{11,13,41,42}$ Furthermore, Levy ${ }^{42}$ points to research completed in the U.K. in the area of children's play contending that parental anxiety has a role to play as $53 \%$ of parents cite worries about traffic and $40 \%$ of parents cite concern about children being snatched by strangers as reasons for reluctance to let children outside. The health services, according to Levy, ${ }^{42}$ have experienced large increases in repetitive strain injuries linked to excessive time spent on ICDs. The lack of social contact from digitally socially isolated childhood experiences referred to by Levy ${ }^{42}$ seems to match the earlier research by Ebbeling et al., ${ }^{41}$ and their identification of psychosocial risks from childhood ICD activity. It could be observed that in addition to the parental mediation risks identified by Livingstone $\&$ Haddon $^{40}$ that there are additional risks, 
such as risks to the long-term health of the child and psychosocial risks.

Livingstone \& Haddon' ${ }^{40}$ research captured the experience of parental mediation as a binary response to a list of rules and parental practices contained within the survey. Appel et al. ${ }^{43}$ make a similar observation to Livingstone \& $\mathrm{Haddon}^{40}$ on the ineffectiveness of parental mediation and the reduction of child risk. However, Appel et al., ${ }^{43}$ contend that it is restrictive parental practices that may be ineffective. Children's online activities may occur in a place that is deemed safe by parents and adolescents have the capability to circumvent parental Internet restrictions and controls. ${ }^{43}$ An observation identifies that while Appel et al., ${ }^{43}$ point to adolescents having the capability to circumvent parental control, it is not implied that children may have a suite of active strategies and tactics designed to specifically counteract or thwart parental mediation strategies or tactics. Critically Appel et al. ${ }^{43}$ make associations between successful parental mediation and activities that benefit the parent-child relationship and positive parental experiences.

\section{Parental Mediation: Potential benefits}

Parent-child relationships can benefit from the instructive and restrictive communication contained in the parental mediation processes. $^{43-45}$ Research indicates that parent-child conversations on the nature, content and risks of websites seem to be a more successful way of mediating ICDs and that better general parent-child relationships are associated with fewer behaviour problems among children and adolescents. ${ }^{43-46}$ The benefits outlined in the parental mediation of risks identified by Appel et al., ${ }^{43}$ and Van den Eijnden ${ }^{46}$ counter the implied relationship between risks and negative outcomes offered by Kirwil. ${ }^{20} \mathrm{~A}$ balanced view suggests that risk may be considered as having the potential of benefits as well as the potential for harm.

Exposure to the content available on ICDs can according to Osit actually contribute to better parenting experiences and lead to better real life experiences for children. This form of parental mediation can help establish or improve a healthy climate of communication between the parent and child. ${ }^{1}$ Children develop their social skills through online interaction while learning about boundaries under parental supervision. ${ }^{6}$ Parental mediation of children's ICDs can be positively shaped through an understanding that children should experience a healthy level of exploration, independence and an appropriate amount of privacy relative to their online activities. ${ }^{47}$ Here, a number of observations can be made. The balance between exploration and privacy implied by Osit ${ }^{1}$ seems to be supported in general parenting models in that Kuhar ${ }^{6}$ puts forward a control-autonomy spectrum. Parental recognition of degrees of appropriate child online privacy as suggested by Osit ${ }^{1}$ could be paralleled with degrees of child autonomy in Kuhar's ${ }^{6}$ control-autonomy spectrum. The balance of controlautonomy has been captured by Meyers \& Gilbert ${ }^{47}$ as the process of the parent simultaneously guiding the child while starting to let go at the same time. Critically, the exposure to ICD content suggested by Osit ${ }^{1}$ goes beyond an understanding of the benefits of child interaction with ICDs as being limited to those such as learning from educational programs or the development of cognitive or motor skills abilities. The literature of Osit ${ }^{1}$ suggests that a parent's knowledge of a child's interests in ICD activities such as social interests, the types of games that they may be interested in or what those games mean to the child, provide a more comprehensive understanding as to the real benefits experienced. A parents knowledge of a child's ICD interests would seem to be of benefit in instructive and restrictive communication, as suggested by Appel et al., ${ }^{43}$ in that conversations on the nature, content, and risks of ICDs may provide a more successful form of parental mediation than purely restrictive parental practices. Research on parental-child trust seems to support the positions of both Appel et al. ${ }^{43}$ and Osit ${ }^{1}$. Parental knowledge of a child's daily activities can, according to Kerr et al., ${ }^{48}$ contribute to increasing levels of parent-child trust. Furthermore, Kerr et al., ${ }^{48}$ contend that parental monitoring should actually be interpreted as parental knowledge. The parent-child communication implicit in developing an understanding of a child's knowledge of interests may be viewed as the link between the parental experience of mediating children's use of ICDs and better parental mediation outcomes referred to by Appel et al., ${ }^{43}$ and Osit. ${ }^{1}$

\section{Parental mediation strategies for children's use of ICDs}

Research indicates that there are two main forms or models of parental mediation of ICDs: Restrictive and instructive. ${ }^{5,20,23,40}$ The restrictive approach to parental mediation of children's use of ICDs can be characterised as the regulation of use through rule-making such as using technical filtering/monitoring tools, restricting social interactions online, parental monitoring of visited websites and checking of e-mails. ${ }^{5,20}$ The instructive approach to parental mediation can be illustrated as a parental (sharing) experience that reflects a parent's active efforts (social co-use) to interpret and translate content and messages for their children. ${ }^{5,20}$ It could be observed that parental mediation may contain elements of parental control, in the form of restrictive strategies, and parental experience contained within the instructive approach to parental mediation.

The two general forms of parental mediation are further expanded on by Livingstone \& Helsper ${ }^{23}$ to include active, restrictive and co-use strategies and can be combined with Baumrind's ${ }^{4,49}$ parenting styles model (authoritarian, authoritative, uninvolved and permissive). An observation highlights that the choice of parents not to mediate children's use of ICDs was not considered by Livingstone \& Helsper ${ }^{23}$ but can be accommodated by Baumrind's parenting styles., ${ }^{4,49}$ Research based on Baumrind' ${ }^{4,49}$ parenting styles by Kuhar ${ }^{6}$ indicates that a control-autonomy continuum is recognisable in parent-child relationships. A critical analysis of the research on the main forms of parental mediation of ICDs infers that parental mediation is in general not thought to be either fully restrictive or fully instructive but that parents may use a combination of both forms (restrictive or instructive) in line with a parental style or the control-autonomy continuum. The literature suggests that parental mediation is dynamic in the sense that it has an ability to be a mix of restrictive or instructive practices. However, the literature does not indicate if there are additional dynamics such as variations in parental mediation due to gender, age or that parental mediation may change on the observation of a child's behaviour such as hiding an ICD screen from parental view. It may also be observed that the literature did not consider the provision of ICDs by parents to children as a form of child minding activity or a type of parental replacement activity. However, Baumrind's,49 parenting style of uninvolved/permissive may be viewed as having the capacity of explaining such a parental mediation strategy.

Parents can respond to cues or triggers that may be present in the environment such as the audio or visual from an ICD and from communication (intentional and unintentional) from a child..$^{50,51}$ While Bernstein $^{50}$ highlights that children engage in deception, Gamble \& Gamble ${ }^{51}$ indicate that verbal and non-verbal behaviours may provide clues to deceptions. In essence, space or distance, hesitations and silence, bodily cues such as gestures or postures or facial expressions 
may all trigger or cue parental curiosity as the type or nature of activity that a child may be engaging in while on an ICD. ${ }^{51}$ Critically, the consideration that parents may respond to specific types of observed behaviour provides a way of understanding how parental mediations might be triggered, thereby creating a way of linking a dynamic parenting response to a change in child behaviour to changes in levels or types of parental mediations.

Inferred within the literature is that children do not adopt selfregulation strategies in their approach to ICD use. An additional observation is the absence of a consideration of the role of trust that the parent may have in the child's ability to successfully self-regulate their interaction with ICDs. The absence of a consideration of child self-regulation strategies or trust between the parent and child could be viewed as a limitation of the main types of parental mediation.

\section{Trust, parenting style and child self-regulation}

Observations have noted the absence of the consideration of trust from literature on parental mediation. Trust can be understood as a firm belief in the reliability, truth, or ability of someone or something and where trust infers an acceptance of the truth of a statement without evidence or investigation. ${ }^{27}$ Parental knowledge of a child's feelings and concerns, knowledge of past delinquency and knowledge of daily activities has been shown by Kerr et al., ${ }^{48}$ to be connected to the way trust develops in the parent-child relationship. Interestingly, Kerr et al. ${ }^{48}$ found that parental knowledge of daily activities influenced trust more then knowledge of a child's past wrong doings and that the knowledge of daily activities came in part from a child's spontaneous disclosure. Effectively, parental knowledge about a child's daily interests coupled with child self-disclosures help build trust in the parent-child relationship..$^{48}$ The lack of research around how trust builds noted by Kerr et al., ${ }^{48}$ seems to correspond with more contemporary texts in that there are only two mentions of trust in Corey's ${ }^{11}$ text on the Theory and Practice of Counselling and Psychotherapy. Critically, while Corey ${ }^{11}$ offered a limited consideration of trust it could be a reflection that the trust is contained within personal belief systems and in personal experience.

According to Meyers \& Gilbert, ${ }^{47}$ trust can be connected to parenting styles. Authoritarian parenting can be distinguished by high levels of control and low levels of autonomy and low levels of parental trust displayed in the child as a result of the parents need/want to control the child's activities. ${ }^{47,52}$ Parents that mix control and autonomy may be viewed as authoritative and trust can be considered to be an element of the parent-child relationship as the parent essentially provides a safe framework for the child to make mistakes, trusting those mistakes will not have long-lasting consequences..$^{47,52}$ Parallels may be drawn between the authoritarian parenting styles and predominantly restrictive parental mediation strategies and between authoritative parenting and instructional methods of parental mediation. .,20,47,52 $^{5}$ The concept of child selfregulation may be considered as similar to that of self-control in that it represents an ability to control impulsive behaviour. ${ }^{8,53}$ Research by Saunders \& Mazzucchelli ${ }^{53}$ highlights that self-regulation can be thought through parenting interventions. A chain of research suggests that a link can be made between parenting styles, parent-child trust and a child's ability to self regulate and control impulsive behaviour. Additionally, Grolnick \& Ryan's ${ }^{52}$ parent-child trust relationship could be critically assessed as being subject to change and dynamic in nature as knowledge of a child's daily interests implies that changes in the levels of knowledge of interests may be reflected in changes in levels of trust. The adage, trust but verify, provides the basis of a final critical evaluation in that a child may have figured out how to attain and hold a parents trust in their ICD activities but actually be engaging in harmful or inappropriate activity. As such, trust could create a blind-spot for parental mediation. Conversely, the child may have parental trust and demonstrate an ability to self-regulate ICD activity.

\section{An Irish perspective on parental mediation and online risk references}

There are more than 308,000 households in Ireland where parents regularly engage in the mediation of children's use of ICDs. ${ }^{54}$ The nature of the parental experience can be in part understood through the make-up of household types where $62 \%$ of households contain two parents in a traditional married relationship, $13 \%$ cohabitating parents and $25 \%$ of parents are lone parents. ${ }^{54}$ Irish parents, according to Mac Cormaic, ${ }^{55}$ are more likely than European peers to monitor and supervise children's Internet activity. Bullying activity on Internet sites such as Ask.fm has been linked with teen suicide. ${ }^{56}$ Abusive content on Ask.fm was given as a reason in the suicide note of a 13year-old girl found by her mother. ${ }^{57}$ Three months later the girl's 15 year-old older sister took her own life, saying in her suicide note that she could not go on without her sister. ${ }^{57}$ Research by O'Neill et al. ${ }^{58}$ helps to contextualise the Irish parental experience in mediating children's ICDs. Most Irish children (93\%) access the Internet at home while $20 \%$ of Irish children have access to ICDs while 'out and about'. ${ }^{58}$ However, O'Neill et al., ${ }^{58}$ did not identify if the access to ICDs while 'out and about' was based on the use of a child's own ICD device or the use of other peoples (friends) devices. Even if children do not have a mobile ICD, they can still use places such as public libraries and Internet cafés to gain access to Internet material. ${ }^{58}$ The Irish children's exposure to online learning, knowledge and risk seems to increase with age profile which may be a reflection of growing child autonomy or a reflection of implicit or explicit trust that parents have in older children to manage their online activities. The research of O'Neill et al. ${ }^{58}$ found that $8 \%$ of $9-10$ year-olds have encountered some risk from online activities. This increased dramatically to $63 \%$ for children aged between 15 -16years old. ${ }^{58}$ Approximately 33\% of Irish children have contact online with someone they have never met and $4 \%$ of children have met the online contacts face to face. ${ }^{58}$ Approximately one in ten children have been exposed to sexual images on line. ${ }^{58}$ The Irish parental experience can be characterised as one where the majority of parents engage in some form of mediation (91\%) and have the highest level of restrictive mediation activity in Europe. ${ }^{58}$ The rate of restrictive strategies does not reveal the complex nature of the Irish parental experience as instructive strategies such as talking to children and helping children deal with online experiences ${ }^{58}$ Similar to other research in the area of parental mediation, the orientation of the research is quantitative in nature and does not explore parental experience in moderating children's ICDs in a qualitative way. An observation could be made that O'Neill et al. ${ }^{58}$ did not consider parents using restrictive techniques, such as banning access to ICDs, to regulate general behaviour, nor what that parental experience may have been like. Critically, the type and nature of the child's emotional response to the parental restrictions or parental style was not explored in O'Neill et al., ${ }^{58}$ research, i.e. did the parents experience arguments because of restricting access to the child's ICDs, highlighting a limitation of the methodology used in the research.

\section{Summary Discussion and Conclusion}

The literature reviewed has informed and provided operational definitions and understandings for potential research constructs of parental experience, parental meditation and ICDs. Links have been 
established between the experience of parents in the mediation of their children's use of ICDs and the general theories of psychology, counselling and psychotherapy approaches. ${ }^{11,13,17}$

Parental mediation has been shown to contain instructive and restrictive practices. ${ }^{20,40}$ Critical analysis observed that parental mediation may be viewed as covert or overt and as containing elements of parental control in the form of restrictive strategies and parental experience contained within the instructive approach to parental mediation. The risks and benefits associated with children's access to ICDs help to provide context. Children's access to ICDs has been associated with content risk, contact risk, conduct risk and violation of privacy. ${ }^{5,20,23,40}$ Child age and gender were identified as online risk factors. ${ }^{40}$ Furthermore, additional risks were identified as health risks such as childhood obesity, repetitive strain injuries and psychosocial risks such as low self-esteem and depression, which are of interest to the area of psychology, counselling and psychotherapy. ${ }^{11,13,41,42}$

The risk of parental anxiety was also identified. Parental anxiety was operationally defined as the experience of anxious feelings or emotions about anticipated or imagined danger experienced by a person in their role as parent. However, the interpretation of risk needs to be balanced in light of the benefits that may also accrue from use of ICDs. ${ }^{3,5,20,23,40}$ The benefits of parents adopting social co-use can bring the experience of enjoyment through the parents and children sitting together and viewing age appropriate content. ${ }^{20,23,40}$

The parental experience of forms of mediation on children's access to ICDs does not appear to be fully understood. It should be noted that the focus of the research reviewed was quantitative in nature where the parenting experience was understood through binary responses in surveys. ${ }^{5,20,40}$ However, critical analysis suggests that parental mediation is a dynamic process where the parental experience can be influenced by a number of factors including knowledge of a child's interests, age, gender, trust and where the experience of child behaviours may cue or trigger a parental intervention or change in parental control.

It is contended that developing an understanding of what the experience of parents is in the mediation of their children's use of ICDs will not just address a gap in research approaches, but may have the potential to inform psychologists and therapists practice. The literature did not imply the type and nature of the child's emotional response to the restrictions, i.e. did the parents experience arguments because of restricting access to the child's ICDs? The literature reviewed did not explore if parent experience included using access to ICDs as a reward or punishment for general child behaviour. Sadly, the risk behaviours identified with ICD use, such as the sharing of pornography or engaging in Nek-nominations, along with the known suicides of two Irish girls, put the risks associated with children's access to ICDs in perspective. ${ }^{35,36,57}$ It is concluded that the review builds a chain of evidence that supports the importance of additional research being completed in the area of Irish parents experience of mediating children's use of ICD's.

\section{Acknowledgements}

We would like to express our thanks to Pat Meehan and Cliona McLoughlin for the initial proof reading of this review.

\section{Conflicts of interest}

Author declares there are no conflicts of interest.

\section{Funding}

None.

\section{References}

1. Osit M. Generation text: Raising well-adjusted kids in an age of instant everything. AMACOM, New York, USA. 2008. p.288.

2. Intel. Embedded intelligent systems: Internet connected devices. 2013.

3. Appel M, Holtzb P, Stiglbauera B, et al. Parents as a resource: Communication quality affects the relationship between adolescents' Internet use and loneliness. J Adolesc. 2012;35(6):1641-1648.

4. Baumrind D. Rearing competent children. In: Damon W (Ed.), Child development today and tomorrow. Jossey-Bass, San Francisco, USA. 1989. p.349-378.

5. Clark L. Parental mediation theory for the digital age. Commun Theory. 2011;21(4):323-343.

6. Kuhar M. Parental authority styles in adolescent-parent relationships. Diskurs Kindheits Und Jugend for schung Heft. 2010;3:321-336.

7. Ross CC. Overexposed and under-prepared: The effects of early exposure to sexual content is the Internet impacting sexual development? Psychology today. 2012.

8. Reber AS, Allen R, Reber ES. Penguin dictionary of psychology. (4th edn), Penguin, London, UK. 2009. p.928.

9. Merrian-Webster Dictionary search for experience. 2013.

10. Santrock JW. Child development. (12th edn), McGraw Hill, New York, USA. 2010. p.640.

11. Corey G. Theory and practice of counselling and psychotherapy. (8th edn), Fullerton, California, USA. 2009. p.544.

12. Cooper M. The challenge of counselling and psychotherapy research. Strathprints, Strathclyde. 2010. p. 27.

13. Feltham C, Horton I. The SAGE handbook of counselling and psychotherapy (2nd edn), SAGE Publications, London, UK. 2006. p.624.

14. Marmarosh CL. Empirically supported perspectives on transference. Psychotherapy. 2012;49(3):364-369.

15. Freud S. The interpretation of dreams (A A Brill Trans) (3rd English Translated Ed.), Macmillan Company, New York, USA. 1913. p.675.

16. Bowlby J. Attachment and loss: Vol 2 separation. Basic Books, New York, USA. 1973. p.462.

17. Hazler RJ. Person-centred theory. In: Capuzzi D \& Gross DR (Eds.), Counselling and psychotherapy: Theories and interventions (5th edn), American Counselling Association, Alexandria, USA. 2011. p.143-166.

18. Whitcombe S. Parental alienation - time to notice, time to intervene. Psychologist. 2014;27(1):32-34.

19. Covington MJ, Carskedden R. Threat implications of the Internet of things. 5th International Conference on Cyber Conflict, NATO CCD COE Publications, Tallinn, Estonia. 2013.

20. Kirwil L. Parental mediation of children's Internet use in different European countries. J Child Media. 2009;3(4):394-409.

21. Daft RL. Organisation theory and design (11th edn), Thomson Leaning, USA. 2012. p. 688 .

22. Kotter J. Homepage of Kotter international. 2014.

23. Livingstone S, Helsper E. Parental mediation and children's Internet use. J Broadcast Electron Media. 2008;52(4):581-599.

24. Biddulph S. Raising boys (3rd edn), Harper Collins, Hammersmith, London, UK. 2010. p.244.

25. Nauert P Mixed parental anxiety over Internet predators [Internet]. 2009. 
26. Calder J. Video game violence review welcomed. Psychologist. 2013;26(11):789.

27. Oxford University Press. Online dictionary [Internet]. 2014.

28. Clarke K, Cooper P, Creswell C. The parental overprotection scale: Associations with child and parental anxiety. $J$ Affect Disord. 2013;151(2):618-624.

29. Cobham VE, Dadds MR, Spence SH. The role of parental anxiety in the treatment of childhood anxiety. J Consult Clin Psychol. 1998;66(6):893-905.

30. Geggel RL, Horowitz LM, Brown EA, et al. Parental anxiety associated with referral of a child to a paediatric cardiologist for evaluation of a still's murmur. J Pediatr. 2002;140(6):747-752.

31. Pereira AI, Barros L, Mendonca D, et al. The relationships among parental anxiety, parenting, and Children's anxiety: The mediating effects of Children's cognitive vulnerabilities. J Child Fam Stud. 2014;23(2):399-409.

32. Spielberger CD, Gorush R, Lushene RE. Manual for the state-trait anxiety inventory (STAI). Consulting Psychologists Press, Palo Alto, USA. 1983. p.42.

33. Richardson A. Porn: Parents screening. 2014.

34. Bartlett J. The tap, tap, tap of child abuse. The Sunday Times, UK. 2014 p.S4-1-S4-2.

35. Broderick R. Everything you need to know about \#NekNomination, the meme that may have killed five people. 2014.

36. Huffington Post. 'Neknominate' Facebook drinking game reaches BC. 2014

37. Irish Independent. Second death linked to online drinking game after body of teenager found. 2014

38. Mail Online. Nek nominations! Australia's new extreme drinking craze. 2014.

39. Irish Heart Foundation. Alcohol and my heart. 2014.

40. Livingstone S, Haddon L. EU kids online: Final report.LSE, London, UK. 2009. p.47.

41. Ebbeling CB, Pawlak DB, Ludwig DS. Childhood obesity: Public-health crisis, common sense cure. The Lancet. 2002;369(9331):473-482.

42. Levy A. Parents' anxieties keep children playing indoors: Fears about traffic and strangers leading to 'creeping disappearance' of youngsters from parks. 2014.
43. Appel M, Holtzb P, Stiglbauera B, et al. Parents as a resource: Communication quality affects the relationship between adolescents' Internet use and loneliness. J Adolesc. 2012;35(6):1641-1648.

44. Holtz P, Appel M. Internet use and video gaming predict problem behaviour in early adolescence. J Adolesc. 2011;34(1):49-58.

45. Lee SJ, Chae YG. Children's Internet use in a family context: Influence on family relationships and parental mediation. Cyberpsychol Behav. 2007;10(5):640-644.

46. Van den Eijnden RJ, Spijkerman R, Vermulst AA, et al. Compulsive Internet use among adolescents: Bidirectional parent-child relationships. J Abnorm Child Psychol. 2010;38(1):77-89.

47. Meyers S, Gilbert K. How parents can protect teenagers, keep them safe, trust. Psychology today. 2012.

48. Kerr M, Stattin H, Trost K. To know you is to trust you: parents' trust is rooted in child disclosure of information. J Adolesc. 1999;22(6):737-752.

49. Baumrind D. The influence of parenting style on adolescent competence and substance use. J Early Adolesc. 1991;11(1):56-95.

50. Bernstein J. Getting Your Lying Teen to Level with You Calm can parents help children stop lying. Psychology today. 2012.

51. Gamble TW, Gamble MW. Interpersonal communications. Sage Publications Inc, New York, USA. 2013. p.496.

52. Grolnick WS, Ryan RM. Parent styles associated with children's self-regulation and competence in school. $J$ Educ Psychol. 1989;81(2):143-154.

53. Saunders RM, Mazzucchelli TG. The promotion of self-regulation through parenting interventions. Clin Child Fam Psychol Rev. 2013;16(1):1-17.

54. CSO. Statistics: People and society. 2013.

55. MacCormaic R. Irish parents monitoring child Internet use.The Irish Times, Ireland. 2008. p. 5.

56. Irish Times. Teen kills herself after cyber-bullying on ask.fm, father says. 2013.

57. Harkin G. Bullying victim Erin Gallagher named the website ask.fm in her suicide note, her mother has said. 2013.

58. O'Neill B, Grehan S, Olafsson K. Risks and safety for children on the Internet: The Ireland report. (No EU Kids Online). LSE, London, Uk. 2011. p.61. 